\title{
Educational Suport for Hypermedia Design
}

\author{
Cristina Portugal \\ Pontifical Catholic University of Rio de Janeiro, Brazil \\ e-mail: crisportugal@gmail.com \\ Rita Maria de Souza Couto \\ Pontifical Catholic University of Rio de Janeiro, Brazil \\ e-mail: ricouto@puc-rio.br
}

\begin{abstract}
This paper presents a project directed towards the production of a book in two versions, printed and digital, with the provisional title of "Design, Education and Technology: support for teaching Hypermedia Design, which constitutes a didactic material to support teaching and research activities for the Design area. The starting point was the work by Dr. Cristina Portugal, funded by National Council for Scientific and Technological Development - CNPq, as a scholarship researcher in a Post-PhD internship in the Graduate Studies in Design Program. Besides the theoretical content itself, the project for the aforementioned book includes studies on information architecture, layout, programming language and navigability, among other aspects. The book will gather issues about Design, Education and Hypermedia aimed at offering resources to enhance the use of multiple languages that converge in hypermedia environments, their applicability, techniques and methods in light of Design in Situations of TeachingLearning. The content for producing didactic material, the object of this project, is partially concluded.
\end{abstract}

Index Terms - Hypermedia design, Design in situations of teaching and learning, E-book

\section{INTRODUCTION}

This study stems from experience accumulated over many years of work with schools and universities of Rio de Janeiro, which resulted in several objects designed as support for didactic activities developed by teachers and students of planning, projects and development courses offered by Arts \& Design Department - Pontifical Catholic University of Rio de Janeiro, Brazil. (DAD/PUC-Rio)

Created in Interdisciplinary Laboratory of Design / Education - LIDE (DAD/PUC-Rio) as a result of experiences related to Design in Education, 'Design in Situations of Teaching-Learning' is a line of research preferably inserted in the academic field and that agglutinates works where there is designer participation in projects geared towards Education at any level Nursery, Elementary, High School, Higher and Advanced - as well as for studies and research related to the teaching of Design in the extra-university, technical, extension, undergraduate and graduate ambits. Its basic principle is to enhance the knowledge acquisition process through artifacts, environments and analog and digital systems. In this perspective, each Design solution represents the search for equilibrium between interests and needs of the teacher and student, as well as of educational institutions.

Fontoura[1] says Design is an ample field that involves and to which different disciplines converge. It can be seen as an activity, as a process or understanding in terms of its tangible results. It can be seen as a function of project management, as a project activity, as a conceptual activity, or even as a cultural phenomenon. It is viewed as a means to add value to things produced by humans and also as a vehicle for social and political change.

Design is an active process that influences society, creating its material culture. From this perspective, Meurer[2] says: The world in which we live is more than the matter that has solidified as form and remained over time. Its form is defined by activity and action is its center. If Design is conceived as oriented towards action, understood as active interaction and creative change, it will not focus on the object only as form. Quite the contrary, designers shall concern themselves with developing interactive process models in which object play an indisputable core role as a means for action. According to this vision, Design relates to the totality of human interaction's concrete and intellectual spectrum, of interaction among people, products and the world in which we live.

Starting with a vision open to inclusion, which characterizes Design's area, this study defends the idea that the Design field has great potential for joint works with Education,

Given the above will be presented a project that project belongs to the research and theoretical line of research Design in Teaching and Learning Situations

This paper presents a project directed towards the production of a book in two versions, printed and digital, with the provisional title of "Design, Education and Technology: support for teaching Hypermedia Design, which constitutes a didactic material to support teaching and research activities for the Design area. The starting point was the work by Dr. Cristina Portugal, funded by National Council for Scientific and Technological Development - CNPq, a scholarship researcher in a Post$\mathrm{PhD}$ internship in the Graduate Studies in Design Program and the Interdisciplinary Laboratory for Design/Education (LIDE), both belonging to the Department of Arts and Design at the Pontifical Catholic 
University of Rio de Janeiro (DAD/PUC-Rio). This research is being supervised by Professor Dr. Rita Maria de Souza Couto.

Besides the theoretical content itself, the project for the aforementioned book includes studies on information architecture, layout, programming language and navigability, among other aspects. The book will gather issues about Design, Education and Hypermedia aimed at offering resources to enhance the use of multiple languages that converge in hypermedia environments, their applicability, techniques and methods in light of Design in Situations of Teaching-Learning. The content for producing didactic material, the object of this project, is partially concluded.

The purpose of Dr. Cristina's Post-PhD internship, which is being carried out at LIDE/PUC-RIO, is to develop studies about the various relationships of the Design in Situations of Teaching-Learning thematic axis, focusing on the development of hypermedia systems that reinforce interaction of its praxis with Education and the society in which it is inserted. Configured in 1997, studies with the theme of Education in Design and Design within the Ambits of Education are the investigation focus of this axis, including Elementary, High School and College education. The basic principle is the critical reflection on objects, systems and languages used in concrete environments or environments mediated by technology where, somehow, one intends to acquire knowledge. This is a broad field that deals not only with the development of an object or a system of objects, but also its understanding, use and efficacy.

For the elaboration of the printed and digital versions of the book, Portugal (2010-2012) conducted an in-depth study of the following themes: Design in Situations of Teaching-Learning; Interface Design; Information Design; Interaction Design; Usability; Hypermedia Design; Information Architecture; Visual Culture, Didactic Pedagogical Concepts for Hypermedia Systems.

The proposal for the Post-PhD internship was originally divided into two parts. The first is already concluded and it will be presented in printed book format as didactic material for classroom and research use.

For the second part, projected for conclusion in October 2012, when Dr. Cristina Portugal will finish her Post-PhD internship, a guide is being elaborated in the form of an e-book. The main purpose is to provide instructions that should precede a hypermedia project within the ambit of Education, that is, make it easier for the reader to make decisions, make choices, plan actions and choose resources, among other issues.

Given the complexity in developing an e-book on Design, it was necessary to add someone to Cristina's research who could carry out the digital project and who had expertise in Media Design. That is how Eliane Jordy Iung, Bachelor in Letters and Master in Design, Mariana Ferreira Gomes Corrêa and Guilherme Cunha da Silva, undergraduate students in Design - certified in Digital
Media from DAD/PUC-Rio became part of this research project with PIBITI/CNPq scholarships, also coordinated by Dr. Rita Couto.

\section{JUSTIFICATION}

As a multidisciplinary activity, Design works with several fields of knowledge, granting an encompassing perspective in project development that solve diverse problems and meet the most varied needs. As an activity with multiple approaches, Design works with several emphases to maximize project objectives.

In the words of Bonsiepe[3], knowledge considered cumulative experiences should be communicated and shared, and the presentation of information/knowledge should be a core task for Design. This idea matches the objectives of the publication that is being prepared, which unites the areas of Design and Education.

In face of the above, this project is justified since the information systems of today are inserted in an environment of permanent challenge that requires updating and development of new forms of presentation, beyond the traditional. In this sense, it becomes fundamental to seek new models, new methods and new approaches for developing hypermedia systems for Education that can provide significant information and create pleasant experiences in the teaching-learning process. Ruberti and Pontes[4], underscore this idea considering the significant advances of information and communication technologies. It is up to the schools of our times to take on the arduous task of incorporating a new form of teaching-learning in their practices and theories, a process geared towards enhancing competencies for the use of multiple languages that converge, as well as the skill to self-manage in situations of communication that construct the new telematic multimedia networks.

Along this same line, Bonsiepe [3] discusses the mode to present information in a non-linear manner, which is to say, as hypertext, in a structure of interconnected semantic nodes (in a network), offering alternatives for navigation. For such, different channels of perception (visual, oral, tactile) and new procedures are used to present the information, especially scientific information. Until now, they are predominantly based on texts. Dealing with these multiple resources - music, images, animation, cinema - requires other competencies or literacies, besides those that are merely discursive, which are rarely found gathered in a single person. This requires teamwork with specialists in cognitive psychology, sound design, music, writing, programming and interactive design.

In consonance with the ideas outlined above, the Design project for a printed and e-book as didactic material will gather and provide Cristina's main reflections during her research for the academic field and for society in general. It may also contribute not only to provide subsidies for planning hypermedia systems, but also to enhance, with educational purposes, those 
competencies needed for the use of multiple languages, improving the standards of Education and making learning more productive and interactive.

Add to this the proponent's prior experience with issues related to this study, which can be evaluated based on the assigning of her name, as coordinator, as a Science Scholarship Holder of Our State, whose results include the Multi-Path Games, which is didactic material to help teach deaf children to read and write and that was developed by the LIDE/PUC-Rio team, in two versions: concrete and multimedia.

Produce two versions of didactic material, one, an ebook, and the other a hard copy book, to provide technical and esthetic knowledge of techniques, materials, supports and etc. for elaborating hypermedia systems.

By achieving this objective, the expectation is to constitute an academic space directed towards in-depth reflection, discussion and practice of Design's conceptual and project activity in the field of hypermedia projects with educational purposes, aimed at redefining its use at school and as a social function.

\section{OBJECTIVE}

Produce two versions of didactic material, one, an ebook, and the other a hard copy book, to provide technical and esthetic knowledge of techniques, materials, supports and etc. for elaborating hypermedia systems.

By achieving this objective, the expectation is to constitute an academic space directed towards in-depth reflection, discussion and practice of Design's conceptual and project activity in the field of hypermedia projects with educational purposes, aimed at redefining its use at school and as a social function.

\section{METHOD AND GOALS}

The methodology being used for developing the e-book, the object of this proposal, was constructed based on references from Garrett[5] and adapted to the context and work flow of LIDE's multidisciplinary team. Project phases "a", "b" and "c" are already being carried out and the others are projected in accordance with timetable shown below.

\section{E-book-Development phases}

a) Data collection: elaboration of the briefing based on a bibliographic and document study that serves as the basis for this research. Discussion of the content studied by Dr. Cristina Portugal to transform it into hypermedia content;

b) Organization of the content: elaboration of conceptual maps; choice of the narrative and definition of visual metaphors; elaboration of the storyboard. Development of the layout. Identification of the interaction possibilities of Design resources in hypermedia projects, analyzing the value of each in assisting with motivation, fun aspects and immersion;

c) Development of hypermedia structure: investigation of resources, tools and platforms for development available to identify those that best adapt to the proposal for the creation of didactic material in e-book form; elaboration of the Interface Design; elaboration of information architecture; elaboration of navigation; production and treatment of static and moving images; diagramming (textual data and images); review of textual data after diagramming.

d) Evaluation, adjustment and approval of graphic interfaces; of diagramming; of navigability.

e) Implementation: development of programming; conducting of tests to verify programming functions; final approval of hypermedia to be made available; publication of the e-book.

\section{Printed book - Development phases}

The content of the already finished printed book will undergo text revision, editing, graphic design, preparation of the originals for printing and for publication.

The objective of Portugal's research (2010-2012) is to present Design as a field that can contribute effectively towards the production of hypermedia interfaces, creating interactions and experiences, important aspects in the cognitive development of the human being. The project's goal is to produce didactic material. As mentioned above, the starting point is the idea that the Design field has great potential for joint work with several areas, and that it has the potential to meet new demands from contemporary society, that is, to enhance competencies for using multiple languages that can be offered by hypermedia systems.

\section{EXPECTS RESULTS}

The expected result for this project is the production of a book in two versions: printed and digital.

The first part of the book will present the theoretical basis for the themes of Design in Situations of TeachingLearning, Visual culture: the dematerialization of Design. For Design in educational hypermedia environments, a bibliographic study conducted in several sources was taken as a basis, such as: books, dissertations, theses, papers, websites, reports and other documents, which made room for reading, analysis, interpretation, registration and organization of information obtained in the identification of strategies in light of Design methodologies.

Besides the three aforementioned chapters for the ebook, the content that comprises the fourth chapter will be provided in digital format with examples, exercises, educational games and hypermedia resources geared towards teaching-learning for developing hypermedia projects. Four thematic axes were chosen to create the 
guidelines that should precede a hypermedia project in educational environments: 1. Design of Information; 2. Design of Interaction; 3. Hypermedia Designa; 4. Didactic-pedagogical concepts. This content will be

In principle, the organization of didactic material in ebook format is: the catalogue record about the author, introduction, preface and the first three chapters that present the theoretical reflections that are concluded will be available in the gray field called Design, Education and Technology (Figure 1). The fourth chapter consists of some already developed topics such as the base structure of its information architecture, its navigability and the theme on color. The content to be made available in each module can be seen in the figure 1 below:

Each theme of the e-book's content will be developed available in the e-book with examples using multiple languages and with several resources that could be used by teachers and researchers as didactic and/or research material.

on topics and sub topics will be presented as an example the theme Hypermedia Design -topic color and the sub topics. Color content; introduction; Hue (CMYK subtractive color; RGB additive color.; chromatic harmony); Saturation (Chroma); Value; contrast; Syntax and Relationships (Syntax and taxonomic relationships semantic relations); bibliography; Learn more / Sites / Applications

Below will be shown some of the screens for the first theme, already developed - Hypermedia Design/ Color. Figure 2, 3 and 4.

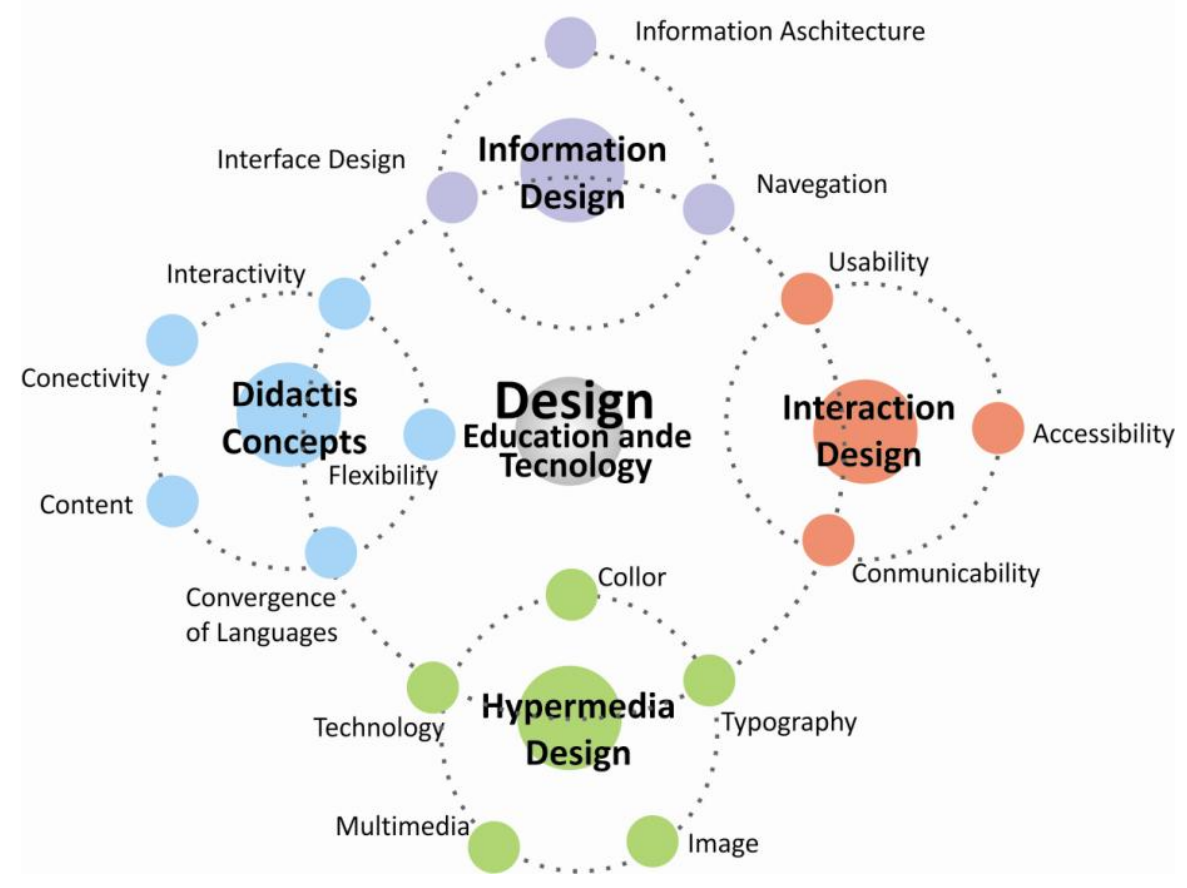

Figure 1: Schematic that shows the content to be made available in each module
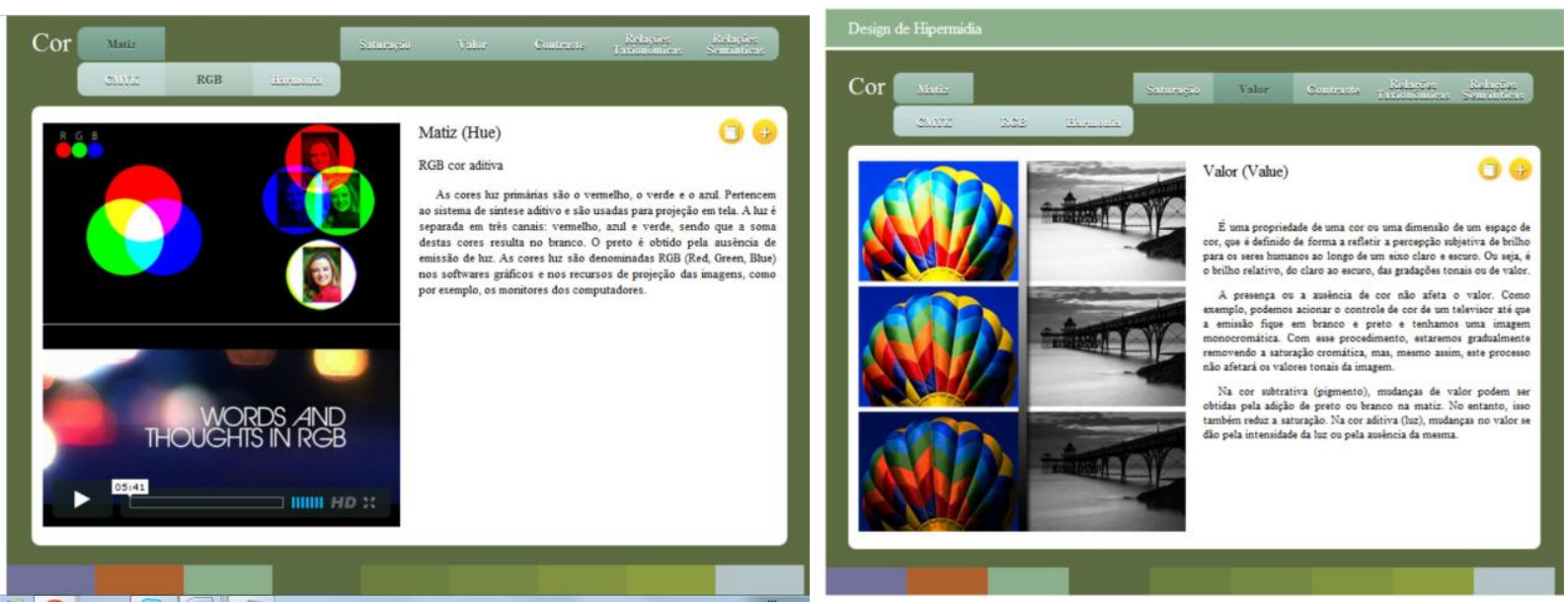

Figure 2: Sreens Matiz and value 

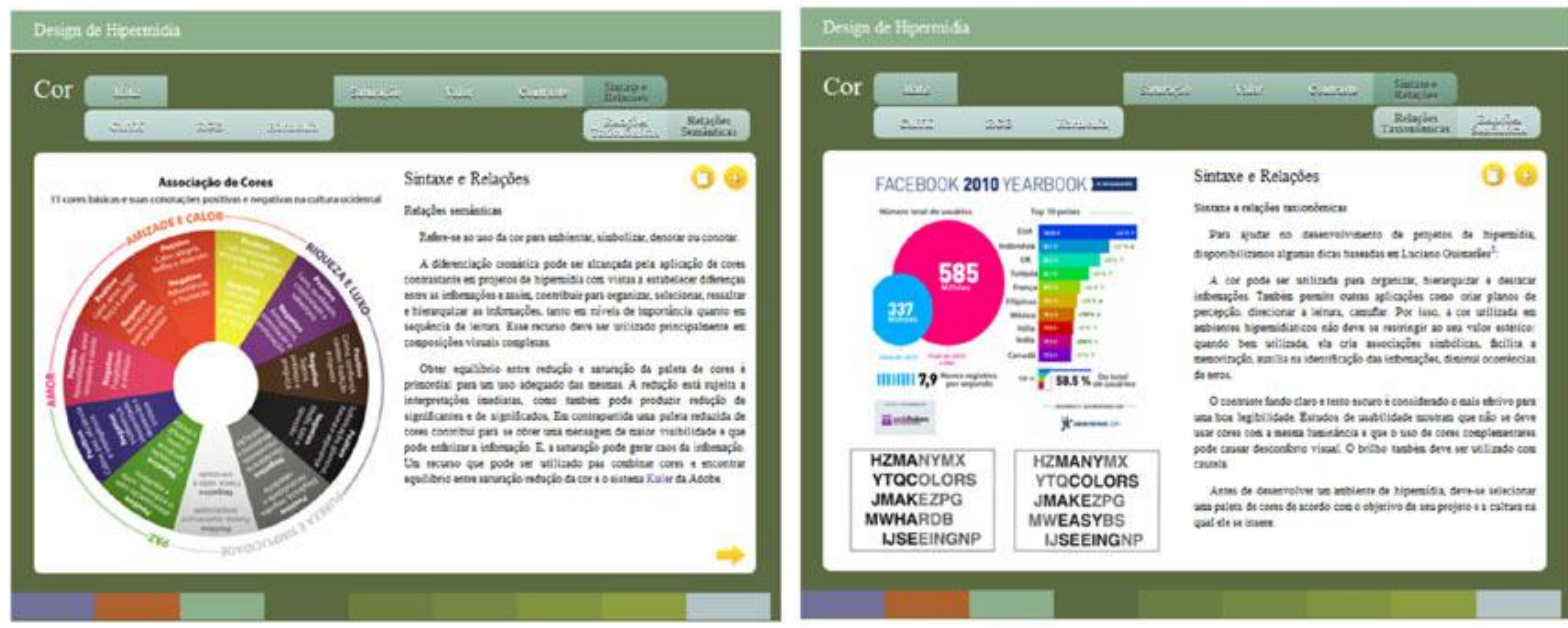

Figure 3: Screens - Syntax and taxonomic relationships semantic relations
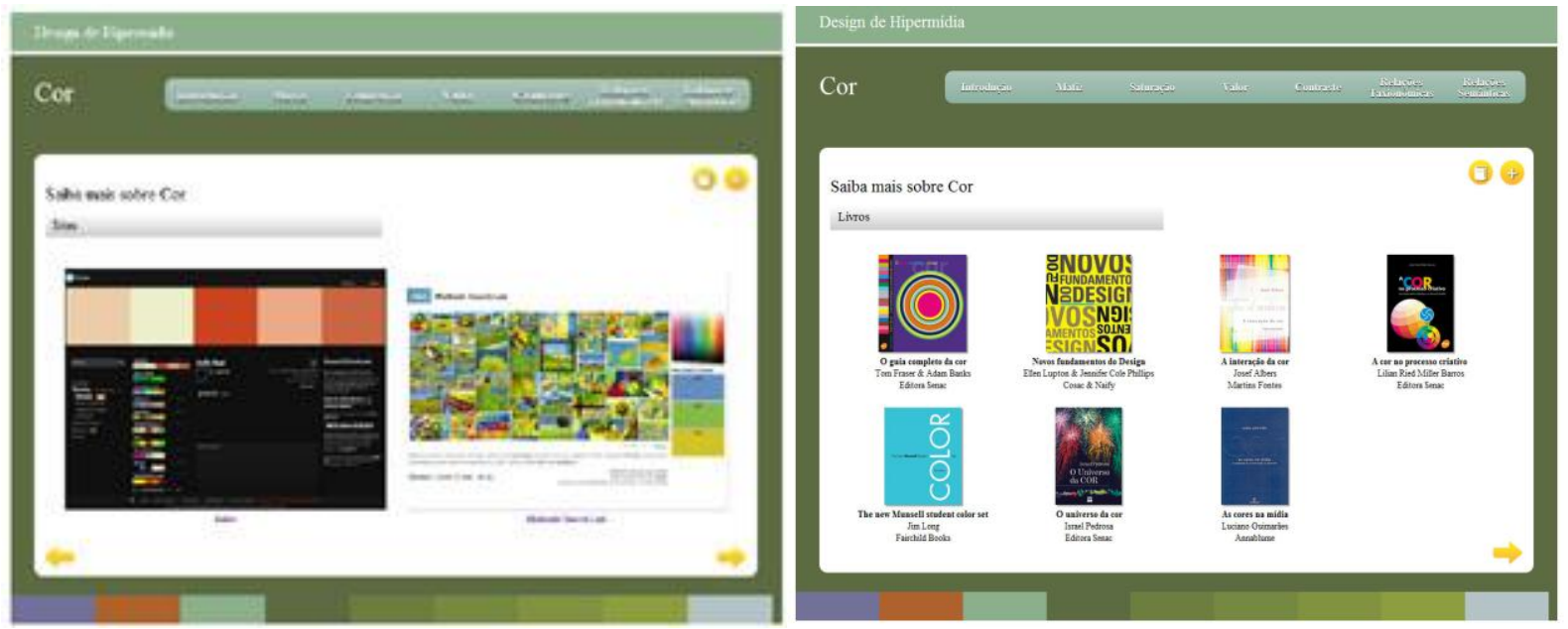

Figure 4: Screens - Learn more, Sites, books, videos and Applications about color

\section{SUMMARY OF THE BOOK CHAPTER}

The contents of this e-book are divided into four modules focusing on major themes, entitled: Information Design, Interaction Design, Hypermedia Design and Dudactic Concepts. These themes are divided into subthemes, presented in a nonlinear way through texts, examples, literature and a topic called "see also". The texts bring aesthetic and theoretical reflections on the role of design in the development hypermedia environments, the samples were selected to illustrate the content of texts and are presented through videos, images etc. The bibliography is divided by topic for easy search, and "See also" consists in a selection of books, websites, games, videos and applications that are intended to provide an environment that enables the reader to enlarge their knowledge into each topic in particular.

Beyond the content in digital format, the book will have a part literature review as presented in the summary below. Summaries of the chapters of the book "Design, Education and Technology: Support for Teaching Hypermedia Design", the object of this study, are shown below.

\section{Chapter 1. Design in Situations of Teaching-Learning}

The discussions that will be carried out, aimed at the core theme of this book, are related to the presence of Design within the ambit of Education.

This chapter presents the Design in Situations of Teaching-Learning line of research defined by Portugal $[6,8,9]$ as a line of research preferably inserted in the academic field and that agglutinates works where there is designer participation in projects geared towards Education at any level - Nursery, Elementary, High School, Higher and Advanced - as well as for studies and research related to the teaching of Design in the extrauniversity, technical, extension, undergraduate and graduate ambits. Its basic principle is to enhance the knowledge acquisition process through artifacts, environments and analog and digital systems. In this perspective, each Design solution represents the search for equilibrium between interests and needs of the teacher and student, as well as of educational institutions.

Design's different subjects are increasingly more involved in projects that require a series of competencies 
aimed at informing designers, not only with the main skill of being able to design objects, but the form of addressing the problems of work that generally lead to innovation. This new profile that is forming, based on the experience of working with interdisciplinary teams with players that have such distinct knowledge, attitudes and culture, while expanding Design's field of action, also requires reflection on the characteristics that define it in several cultures that are in constant change.

In consonance with the changes occurring in contemporary society, as an object of study, content was selected that could be used to work on design experiences in educational environments through multidisciplinary experiences. At LIDE, this theme has been an object of study, since one of the objectives of the Design in Situations of Teaching-Learning line of research is to enrich processes related to teaching and to learning. Interconnections between several fields of knowledge can be seen through this investigation, creating subsidies for planning educational hypermedia environments from a multiple and inclusive perspective.

\section{Chapter 2. Visual culture: the dematerialization of Design}

This chapter of the book reflects on the importance of the investigation of visual culture for the field of Design and its influence on it. The need to investigate areas of knowledge related to Design is growing in importance because, as pointed out by Bonsiepe, the field of Design lost its substance when it began to deal with superficialities, placing itself at the service of cosmetic beauty and aimed at achieving easy profits in the market. The author also suggests the field of Design be treated as any other consolidated subject of science and invest in research, which would permit the generation of knowledge and the formation of a solid framework and foundation for area studies.

From this perspective, this book provides knowledge aimed at generating reflections to improve the design practice, making the design more aware to offer effective solutions in terms of educational hypermedia environments. The result of a Design project in the public environment, whether an analog, digital or communicational artifact has a cultural impact and influences our experiences. This impact affects how people relate to the artifacts, to other people, to our environment, and it contributes towards the creation of a cultural consensus.

Beginning with an open perspective of the inclusion that characterizes Design, it defends the idea that this field of knowledge has great potential for joint work with Education, aimed at meeting contemporary society's new demands. It was precisely this understanding that conducted the reflections made herein about the possibilities of an interdisciplinary dialogue between Design and Education based on the effects technologies are having on image, language and culture.

\section{Chapter 3. Design in educational hypermedia environments}

A significant issue in today's world is the avalanche of new technologies with which we interact every day. The technological transformations and their social, ethical, cultural, educational and environmental consequences, among others, are processed at a fast pace, producing new forms of interaction and experience. In face of this fact, it becomes fundamental to seek new models, new methods and new approaches for Design in the context of interaction.

Through a bibliographic review, this chapter aims at discussing issues concerning information and communication technologies in light of Design, addressing aspects of interaction and related to the creation of experiences, starting from the principle that Design has the social function of making environments intelligible.

In face of this fact, it finds support in the ideas of Kerckhove[7], who discussed the relationship of Design, technology and culture aimed at problematizing Design's relationship within the context of interaction, the theme of this paper. For the author, there are clearly more issues in Design than to contain and to seduce. In a broader sense, Design performs a metaphorical role, translating functional benefits into cognitive and sensorial modalities Design finds its form and its place as a species of harmonic sound, and echo of technology. Design frequently echoes the specific character of technology and it corresponds to its basic impulse. Whether the exterior form of cultural artifacts is visible or texturized, Design emerges as that which we could call the skin of culture.

Adopting the ideas outlined above, Design is presented as a field that can contribute effectively towards the production of hypermedia interfaces, creating interactions and experiences, important aspects in the cognitive development of the human being.

\section{Chapter 4. Guidelines that should precede a hypermedia project}

This chapter presents the guidelines that should precede a hypermedia project within the ambit of education in the form of a guide to facilitate the reader to make decisions, makes choices, plan actions and choose resources, among other matters.

In order to develop these guidelines, continuation was given to studies from the Master's in Design taken by the author of this project, where issues were discussed about the computer interface as a mediator for interaction between people in the process of teaching-learning and Design methods based on Human-Computer Interaction (HCI) approaches, among other aspects.

The referred to research resulted in the elaboration of a Guide for the Analysis of the Interface Design - GADI (see [6] for a comprehensive survey), aimed at testing aspects of usability in learning environments in light of Design methods and techniques. GADI was revised and 
expanded in this study. Add to this research the studies for the $\mathrm{PhD}$ (see [7] for a comprehensive survey) taken by Dr. Cristina Portugal, titled 'Design in Situations of Teaching-Learning: an interdisciplinary dialogue', where, using Design methods and techniques, an attempt was made to identify how this area of knowledge can participate in teaching-learning processes to configure pedagogical materials as well as enhance the knowledge acquisition process. Besides the specific investigations that are being carried out for this study.

The content that comprises this chapter will be obtained through the analysis and synthesis of material content raised during this investigation and GADI. Four thematic axes were chosen to create the guidelines that should precede a hypermedia project in educational environments, as presented above: 1. Design of Information; 2. Design of Interaction; 3. Hypermedia Designa; 4. Didactic-pedagogical concepts. As seen before in figure 1 .

\section{CONCLUSIONS}

This study was based on the ideas of Bonsiepe[1] (2011), who considers knowledge experience acquired through means of information and the presentation of such should be a core task for Design. Padovani and Moura[10], who ascertain the importance of experience acquired through our perceptions, support this idea: What we perceive is not a copy of reality. Quite the contrary, the human processing system constructs a model of the world through transformation, expansion, distortion or even disposal of information captured by our senses. When we perceive letters, images, sounds, videos and animations in a hypermedia system, we reconcile sensorial stimuli as well as previously stored knowledge. Our ability to perceive these objects is thus the result of our prior experience and knowledge and the expectations we create about how information should be presented in this media.

According to the LIDE research group's understanding, all educational materials designed must offer possibilities for interpretation that demand development of reasoning and the active participation of interpreters and not just a simple unilateral use relationship. The option for developing a e-book occurred due to the fact that digital language implies all forms of communication tied to orality, writing, image, sound, color, actions, feelings and values.

How the information is made available, transmitted and organized in learning environments implies a series of factors that shall contribute towards the teachinglearning process or not, altering relationships and implies interactions between teachers and students. Assuming that the work with the student of contemporary cannot be limited to the reading and writing process, but rather to an entire language acquisition job, in this study, we intend to address methods for the hearing impaired to acquire hypermedia language within a multisensory perspective.
The book, the object of this study, intends to provide theoretical and esthetic reflections on Hypermedia Design as well as to discuss the role of Design in the development of digital environments, with the intent to promote the enhancement and enrichment of the construction of legible communicative discourse in hypermedia systems, taking into account the concepts of a new time of connectivity, interactivity and nonlinear navigability.

\section{ACKNOWLEDGMENT}

This paper is fully supported by National Council for Scientific and Technological Development - CNPq Process 152351/2010-8 - Junior Post-PhD (PDJ (20102012). The team of the Interdisciplinary Laboratory of Design and Education - LIDE (DAD/PUC-Rio), Eliane Jordy Iung and students Mariana Ferreira Gomes Corrêa and Guilherme Cunha da Silva, that are members of the research group for the development of this book.

\section{REFERENCES}

[1] A. Fontoura M. EdaDe - Educação de crianças $e$ jovens através do design. Florianópolis, 2002. 337p. Tese (Doutorado em Engenharia da Produção) Programa de Pós-Graduação em Engenharia da Produção, Santa Catarina: UFSC, 2002.

[2] B. Meurer. User-Centred Graphic Design: In. Frascara, Jorge, Meirer, Bernd, Toorn, Jan van, Wonckler, Dietmar. Mass Communication And Social Change. CRC Pres, 1997.

[3] G. Bonsiepe. Design, Cultura e Sociedade. São Paulo: Edgar Blucher, 2011.

[4] I. Ruberti and A. Pontes. Mídia, educação e cidadania: considerações sobre a importância da alfabetização tecnológica audiovisual na sociedade da informação. Educação Temática Digital, Campinas, v. 3, n. 1, p. 21-27, dez. 2001.

[5] J. J. Garrett. The elements of user experience: user centered design for web and beyond. $2^{\mathrm{a}} \mathrm{ed}$. New York: New Riders Press, 2010.

[6] C. Portugal. Design em Situações de Ensinoaprendizagem. Rio de Janeiro: Estudos em Design, 2010.

[7] D. Kerckhove. Skin of Culture. London: Kogan Page. 1998.

[8] C. Portugal. "Design como interface de comunicação para ambientes de aprendizado mediados pela internet”. Dissertação (Mestrado em Design). Departamento de Artes \& Design. Pontifícia Universidade Católica do Rio de Janeiro, Rio de Janeiro, 2004.

[9] C. Portugal. Design em Situações de Ensinoaprendizagem. Um diálogo Interdisciplinar. 2009. 206p. Tese (Doutorado em Design), Departamento de Artes \& Design. Pontifícia Universidade Católica do Rio de Janeiro, Rio de Janeiro, 2009.

[10] S. Padovani and D. Moura Navegação em hipermídia. Rio de Janeiro: Moderna. 2008. 
Dr. Cristina Portugal is a $\mathrm{Ph}, \mathrm{D}$ and Master in Design and Graduated in Visual Communications from the Pontifical Catholic University of Rio de Janeiro (PUCRio). Doctoral Internship Abroad PDEE with the Seville University. Specialization in Graphic Design from the U. C. Berkeley Extension California, USA. She is leading the research group Pedagogy of the National Council for Scientific and Technological Development - CNPq and Interdisciplinary Design / Education LIDE - Currently bond Scholar Postdoctoral $\mathrm{CNPq}$ program in the Graduate Design at PUC-Rio.
Dr. Rita Maria de Soiza Couto has Master in Education and $\mathrm{Ph} . \mathrm{D}$ in Education and Graduated in Industrial Design and in Visual Communication from the Pontifical Catholic University of Rio de Janeiro. Is Associate Professor pf the Departmentof Art and Design at the Pontifical Catholic University of Rio de Janeiro, Permanent Teacher of the Post-graduate Design at PUCRio. It is leading the research group Pedagogy of the $\mathrm{CNPq}$ and Design coordinator of the Interdisciplinary Laboratory for Design / Education; in the Pontifical Catholic University of Rio de Janeiro. 